\title{
The Acquisition and Expression of a Peptidergic Phenotype in the Grasshopper Embryo'
}

\author{
HAIG KESHISHIAN ${ }^{2}$ AND MICHAEL O'SHEA \\ Committee on Neurobiology, The University of Chicago, Chicago, Illinois 60637
}

\begin{abstract}
We have examined the developmental acquisition and regional expression of the neurotransmitter proctolin in neurons of the grasshopper embryo, using both assay and immunocytochemistry. There are four stages in the acquisition and accumulation of proctolin in the embryo. The first stage (50 to $60 \%$ embryogenesis) consists of a slow accumulation of proctolin prior to the onset of central nervous system (CNS) staining. During the second stage proctolin levels increase at a 5-fold faster rate. During this stage, which ends at $70 \%$ of development, a stable pattern of staining is established in the ganglia. The third stage (70 to $95 \%$ embryogenesis) consists of a rapid accumulation of peripheral proctolin levels that occurs principally in motor endings, without a significant increase in the CNS. This stage also correlates with the onset of peripheral staining. During the fourth stage, over the final $5 \%$ of embryogenesis, there is a $20 \%$ loss of proctolin in the periphery. We have attempted to relate these changes to developmental events occurring in identified clusters of neurons, by examining the development of neuromuscular connections made by embryonic terminal ganglion motoneurons to the intrinsic muscles of the hindgut. Of the $\mathbf{3 0}$ hindgut motoneurons, only six anterior medial (AM) efferents are proctolin immunoreactive in the embryo. Their axons establish a dense proctolin-staining arborization over the intrinsic muscles. The peptide accumulates in the endings as staining appears in the terminal ganglion. Hindgut proctolin levels increase substantially and then decline in a manner similar to that found for total peripheral proctolin. By the end of embryogenesis the endings will release proctolin, in a calcium-dependent manner, when depolarized. The six proctolin-staining AM neurons constitute a simple model system for studying the determination and expression of neurotransmitters in identified embryonic cells.
\end{abstract}

In the preceding paper (Keshishian and O'Shea, 1985) we used high pressure liquid chromatography (HPLC), a sensitive bioassay, and immunocytochemistry to examine the distribution of the neurotransmitter proctolin in the CNS of the postembryonic grasshopper.

Received May 29, 1984; Revised November 6, 1984;

Accepted November 9, 1984

${ }^{1}$ We thank Jane Witten and Mary Kate Worden for advice and for criticism of the manuscript. The work is supported by National Institutes of Health Grant NS06864-01 (H. K.) and National Science Fourldation Grant BNS 8202515 (M. O.).

${ }^{2}$ To whom correspondence should be sent, at: Department of Biology, Yale University, Box 6666, Kline Tower, New Haven, CT 06511.
We demonstrated the presence of proctolin in the CNS and have identified more than 70 proctolin-staining motoneurons and interneurons in the hatchling. These observations form the prelude to this study, which is concerned with the embryonic acquisition and expression of the neurotransmitter in these cells and in developing neuromuscular junctions.

The grasshopper embryo is a favorable preparation for studying the embryogenesis of uniquely identifiable neurons. Both grasshopper embryos and their neurons are relatively large and are accessible for observation and micromanipulation throughout neurogenesis and development. Using contrast enhancement microscopy, immunocytochemistry, intracellular dye fills, and other methods, it is possible to identify uniquely central and peripheral neurons and to trace their cell lineages to uniquely identifiable precursor cells. The mechanisms of neuronal ontogeny (Bate, 1976; Keshishian, 1980; Bate and Grunewald, 1981), determination (Goodman et al., 1981; Kuwada and Goodman, 1983; Taghert et al., 1984), and differentiation and expression (Bentley and Toroian-Raymond, 1979; Goodman and Spitzer, 1979; Goodman et al., 1979; Shankland and Goodman, 1982), as well as axon guidance and cell recognition (Bentley and Keshishian, 1982; Bentley and Caudy, 1983; Keshishian and Bentley, 1983; Raper et al., 1983), have all been recently examined at the

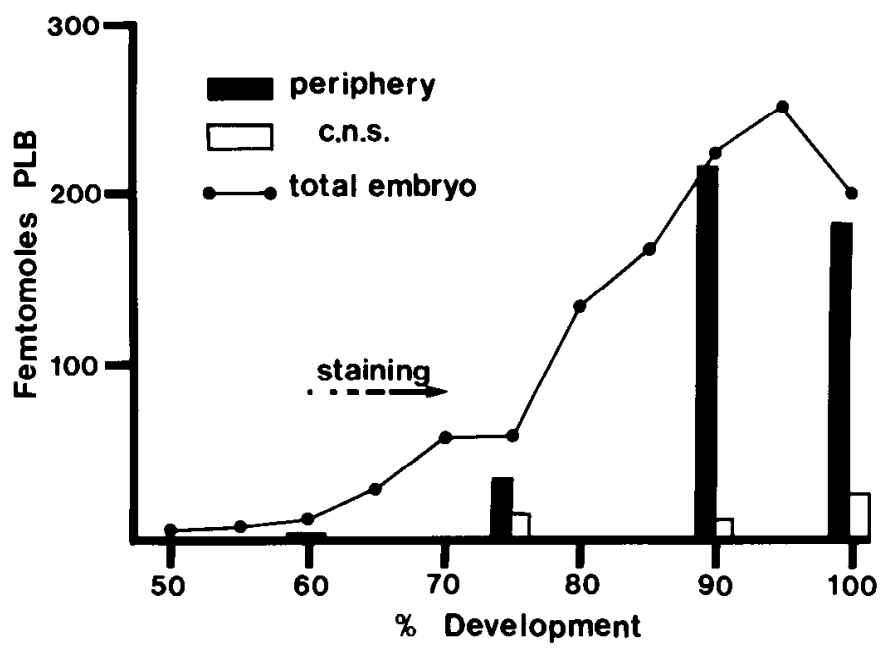

Figure 1. The accumulation of proctolin in the embryonic grasshopper Whole embryo levels of the neuropeptide (solid circles) are first detected by the $50 \%$ stage and increase to $8 \mathrm{fmol} / \mathrm{embry}$ by the $60 \%$ stage, when CNS staining is first detected in the brain. By the $70 \%$ stage, when proctolin immunoreactivity is found throughout the CNS, whole embryo levels have reached $60 \mathrm{fmol}$. Over the next $25 \%$, proctolin levels increase over $300 \%$ to a peak value of $250 \mathrm{fmol}$ at the $95 \%$ stage. Comparison of CNS (open bars) and peripheral levels (solid bars) shows that central proctolin remains relatively stable over this period, and that the increase in net levels is due to accumulation in the periphery. During the last $5 \%$ of embryogenesis both whole and peripheral levels of proctolin are depleted by $20 \%$. This depletion coincides with bouts of motor activity that precede hatching and ecdysis. 


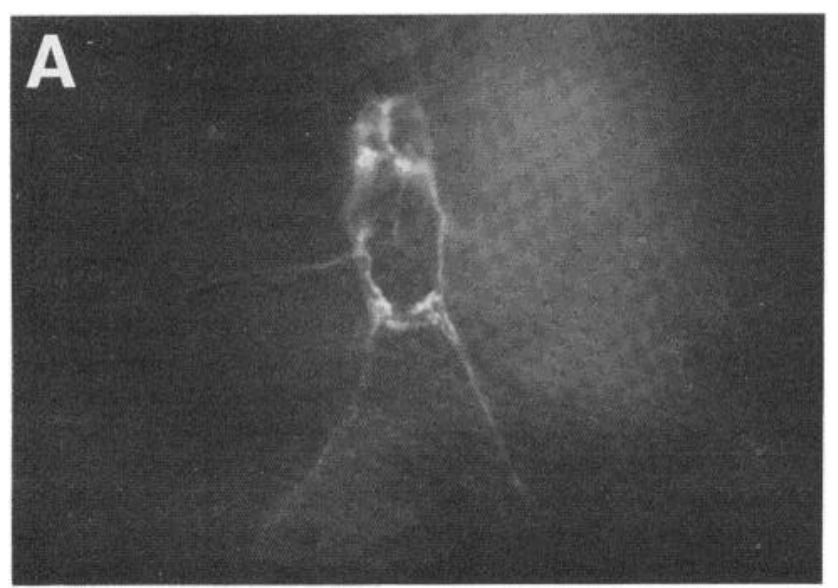

틈

B
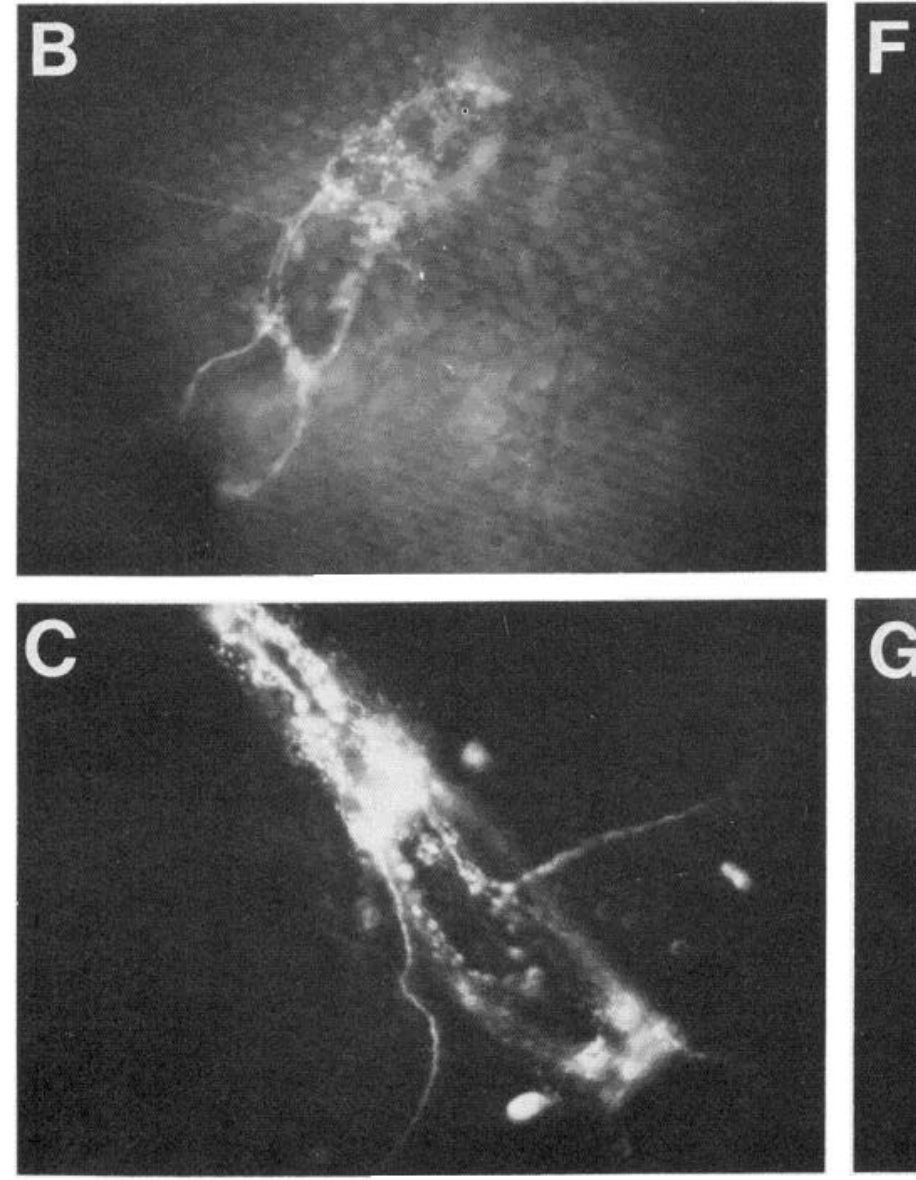

G
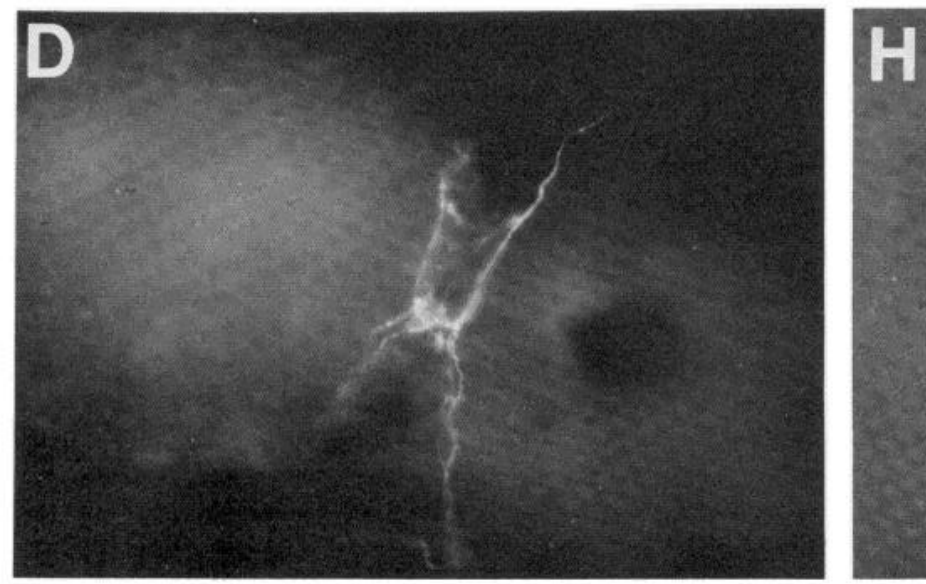
level of singly identified cells and neurons of the grasshopper embryo.

The development of clonally related neurons has been studied in detail in the grasshopper embryo by Goodman and Spitzer (1979, $1981 a, b)$ and Goodman et al. (1979). They described the development of several neuronal phenotypes expressed within a single clone produced by the dorsal unpaired medial (DUM) neuroblast. Their studies show that the clonally related DUM neurons exhibit a range of morphological and electrophysiological properties, while sharing a common transmitter type, octopamine. In this paper we focus on a single rarely expressed neuronal phenotype, the neurotransmitter proctolin, that is found in a wide variety of clonally unrelated neurons of the CNS. Here we describe the embryonic acquisition of the transmitter, its regional expression, and its accumulation in developing synapses.

We find that proctolin appears immunocytochemically in single identified neurons some $40 \%$ in development after the onset of neurogenesis. The expression of proctolin is thus a late arising phenotype, occurring after neurons have already undergone much of their morphogenesis and have acquired active membrane properties. By the 70 to $75 \%$ stages a stable population of central neurons is expressing proctolin in the embryo, and the levels of embryonic CNS proctolin remain relatively stable thereafter. As proctolin can act as an insect neurotransmitter (Brown, 1975; Adams and O'Shea, 1983), we wished to study its accumulation in developing synaptic connections, using the motor innervation of the embryonic hindgut as a model system. We have uniquely identified several of the hindgut motoneurons and examined the time course of embryonic expression using both immunocytochemistry and assay. We have also obtained evidence that proctolin acts as a neuromuscular transmitter at hindgut muscles, and find that proctolin release is functional by the end of embryogenesis.

\section{Materials and Methods}

Grasshoppers (Schistocerca nitens) were obtained from our colony at the University of Chicago. Embryos were staged according to the morphological criteria of Bentley et al. (1979), which define $5 \%$ time increments in embryonic development, beginning at oviposition, and with the $100 \%$ stage defined as hatching. Embryos were incubated at $31^{\circ} \mathrm{C}$, at which temperature embryogenesis takes about 25 days.

Putative proctolinergic neurons were demonstrated in the embryo using the immune sera described by Bishop et al. (1981). In general we used indirect immunofluorescence with either fluorescein isothiocyanate (FITC)- or tetramethylrhodamine isothiocyanate (TRITC)-labeled anti-rabbit lgG, as described by Keshishian and O'Shea (1985). Embryos younger than the $50 \%$ stage were stained tor immunochemistry with the nerve cord left in situ, but with the embryonic membranes, yolk, and dorsal closure removed. In older embryos we dissected out and stained the isolated CNS. Although we did not pretreat the embryos with colchicine, a method found to improve whole mount staining in Periplaneta (Bishop and O'Shea, 1982), we had not noticed a substantial improvement in staining when this method was used postembryonically (Keshishian and O'Shea, 1985). We also did not observe any advantage in desheathing the ganglia for immunochemistry in the embryos. We use the term "proctolin staining" to denote those cells demonstrating positive immunocytochemistry.

For intracellular dye fills we used $90 \%$ stage or older embryos. Terminal ganglia were isolated, desheathed on the ventral side, and affixed to glass microscope slides with fine hairs as described by Keshishian and Bentley (1983). In some preparations we left the innervation to the abdominal musculature intact. The ganglia were observed with water immersion optics with Nomarski differential interference contrast, and the cell bodies were impaled with microelectrodes containing Lucifer yellow, $10 \%$ in $\mathrm{dH}_{2} \mathrm{O}$ in their tips. The electrode shafts were filled with $1 \mathrm{M} \mathrm{LiCl}$, yielding electrode resistances of about 250 megohms. The dye was iontophoresed with a DC -100 - to $-250-p A$ current for 5 to $10 \mathrm{~min}$. The ganglia were fixed a minimum of $20 \mathrm{~min}$ in $4 \%$ paraformaldehyde in $50 \mathrm{~mm}$ phosphate buffer, $\mathrm{pH} 7.3$. Dye fills prepared in this fashion were then co-labeled for proctolin staining as described previously (Keshishian and O'Shea, 1985). Following a final distilled water rinse, the ganglia were mounted in a solution of $5 \% n$-propyl gallate in glycerine, $\mathrm{pH} 7.3$, to retard fading.

We backfilled hindgut motoneurons from the terminal ganglion by placing the rostral and/or caudal branches of the rectal nerve (Seabrook, 1968) overnight in a pool of $0.1 \mathrm{M}$ hexamminecobalt(til) in $\mathrm{dH}_{2} \mathrm{O}$, using minimally dissected adult males and females. Following ammonium sulfide precipitation and wash, the ganglia were fixed in Carnoys and intensified using the tungsten/silver method of Gallyas as modified by Davis (1982). Alcoholdehydrated ganglia were cleared in methyl benzoate and whole mounted between coverslips in Canada balsam.

The extraction, chromatographic purification, and bioassay of the neuropeptide proctolin was performed as previously described (Keshishian and O'Shea, 1985). For the whole embryo assays we removed extraembryonic yolk and all membranes. CNS levels were obtained from dissected brains and nevve cords, with the nerve roots cut close to the ganglia. The peripheral levels were assayed from the tissue remaining after the CNS ganglia had been removed.

We routinely used Sep-Pak $C_{18}$ cartridges for isolating embryonic proctolin prior to its bioassay. These cartridges were found to be suitable for proctolin purification in embryos when we compared the levels of bioassayed proctolin to aliquots that were further purified using a stringent reverse phase HPLC system (Keshishian and O'Shea, 1985). There were no significant differences between the two protocols for embryonic extracts at the $60 \%, 75 \%, 90 \%$, and $100 \%$ stages.

The calcium-dependent release of proctolin under depolarizing potassium concentrations followed the methods described by Adams and O'Shea (1983). We dissected out the entire hindgut excluding the extrinsic musculature from $100 \%$ stage embryos, cutting the rectal innervation close to the muscle. The muscles were layered under physiological saline $(140 \mathrm{mM} \mathrm{NaCl}$. $5 \mathrm{~mm} \mathrm{KCl}, 5 \mathrm{~mm} \mathrm{CaCl}, 1 \mathrm{~mm} \mathrm{MgCl}, 4 \mathrm{~mm} \mathrm{NaHCO}, 5 \mathrm{~mm}$ TES, $5 \mathrm{~mm}$ trehalose, $100 \mathrm{~mm}$ sucrose, $\mathrm{pH} 7.2)$ on the stainless steel screen of a 13$\mathrm{mm}$ Millipore Swinney adaptor. Saline was passed through the adaptor at a rate of $1 \mathrm{ml} / \mathrm{min}$ to perfuse the muscles. Following a $30-\mathrm{min}$ initial equilibration, the muscles were exposed successively for 10 -min periods to several salines designed to depolarize and repolarize them in the presence or absence of normal calcium levels (refer to Fig. 7 for saline compositions). During each exposure the perfused saline was drawn through a Sep-Pak cartridge, which concentrated the released peptide. The proctolin was recovered and bioassayed as previously described (Keshishian and O'Shea, 1985).

\section{Results}

We have examined the neuronal distribution and regional expres sion of the neuropeptide proctolin in grasshopper embryos staged at $5 \%$ intervals (see Bentley et al., 1979, for staging criteria). Both whole embryo and tissue levels of proctolin were assayed, and the expression of proctolin in single identified embryonic neurons was examined using immunochemistry. We have also examined the development of neuromuscular connections made by embryonic terminal ganglion motoneurons, as a model for synaptogenesis by peptidergic neurons.

\section{Acquisition of proctolin in the embryo}

The levels of proctolin in embryos younger than the $50 \%$ stage of development are below our lower limit of detection $(0.2 \mathrm{fmol} /$ embryo). Proctolin was not detected in the yolk or extraembryonic tissues but appeared spontaneously in embryonic tissue during the second half of embryogenesis. Shortly following the onset of mea-

Figure 2. Embryonic proctolin immunoreactivity in the subesophageal and thoracic ganglia. $A$ to $C$, Dorsal view of the subesophageal ganglion, showing the onset and elaboration of neuropilar staining. $A$, Early neuropilar staining at the $65 \%$ stage. $B$, Elaboration of fine neuropilar processes and punctate staining, suggestive of synapses, $85 \%$. C, Intense and extensive neuropilar staining. The laterally directed axons project out of the plane of focus to the ventral side, $95 \%$ stage $D$ and $E$, Dorsal view of proctolin-staining neuropil in the prothoracic $(D)$ and mesothoracic ganglia $(E) ; 70 \%$ stage embryos. $F$, Ventral view of metathoracic ganglion, showing the two pairs of anterior and posterior VM interneurons; $80 \%$ stage embryos. The arrow indicates the location of one of the posterior VM cell bodies. G, Dorsal view of the metathoracic ganglion, illustrating the anatomy of the posterior ventral VM interneurons; $80 \%$ stage embryos. The arrows indicate the neurites projecting from the somata of the VM cells. $H$, Proctolin staining of the two PDL neurons of the metathoracic ganglion (white and black-white arrows); 70\% stage embryos. Indirect FITC (TRITC in $H$ ) fluorescence. Scale, $A$ to $G: 50 \mu \mathrm{m} ; H:=30 \mu \mathrm{m}$. 

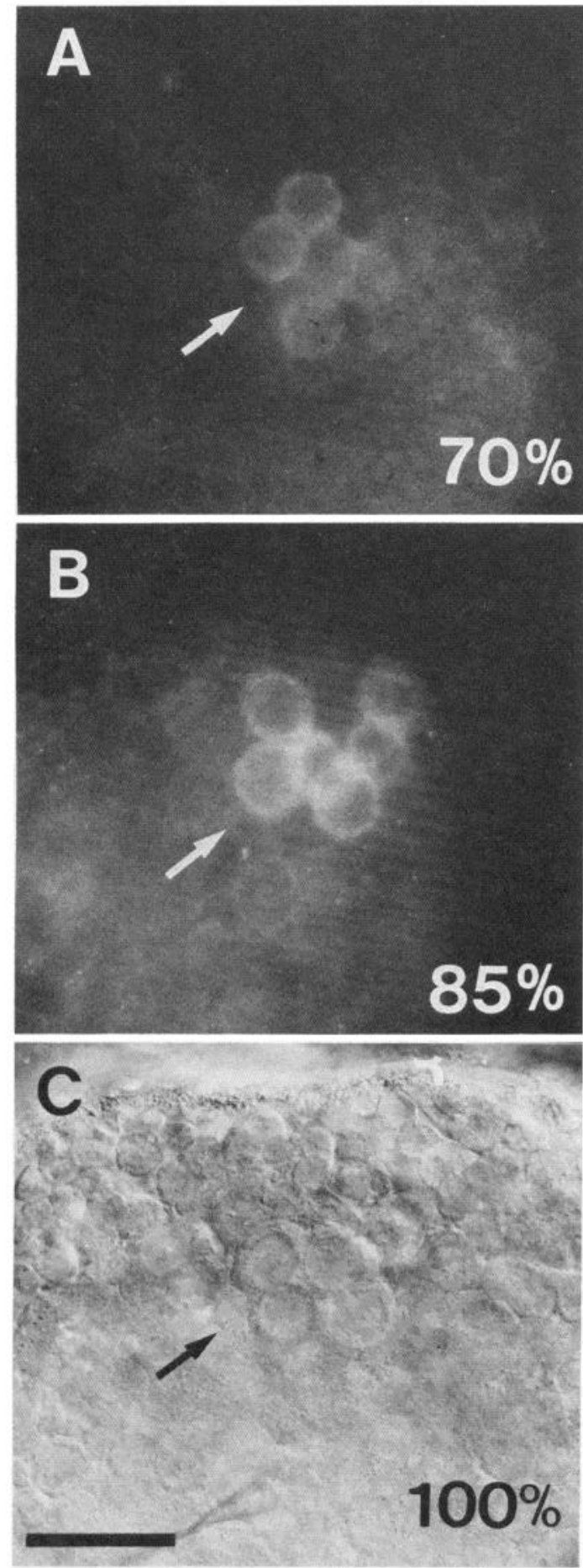

Figure 3. The AM neurons of the terminal ganglion of the embryo. $A$ and $B$, Embryonic terminal ganglion immunoreactivity is acquired by $A M$ neurons at the $70 \%$ stage and remains stable thereafter. The PM neuron cluster of this ganglion appears about 1 day post-hatching (e.g., Fig. $5, A$ to $C$ ). $C$, The appearance of a living, unstained $100 \%$ stage terminal ganglion, viewed ventrally with Nomarski optics, prior to intracellular dye-filling of candidate AM neurons. There are from 6 to 10 relatively large (about $25 \mu \mathrm{m}$ ) cell bodies in this region of the ganglion, which includes ventral members of the AM cluster. At this focal plane, four possible AM cells are clearly seen (arrow). Calibration bar $=50 \mu \mathrm{m}$.
A
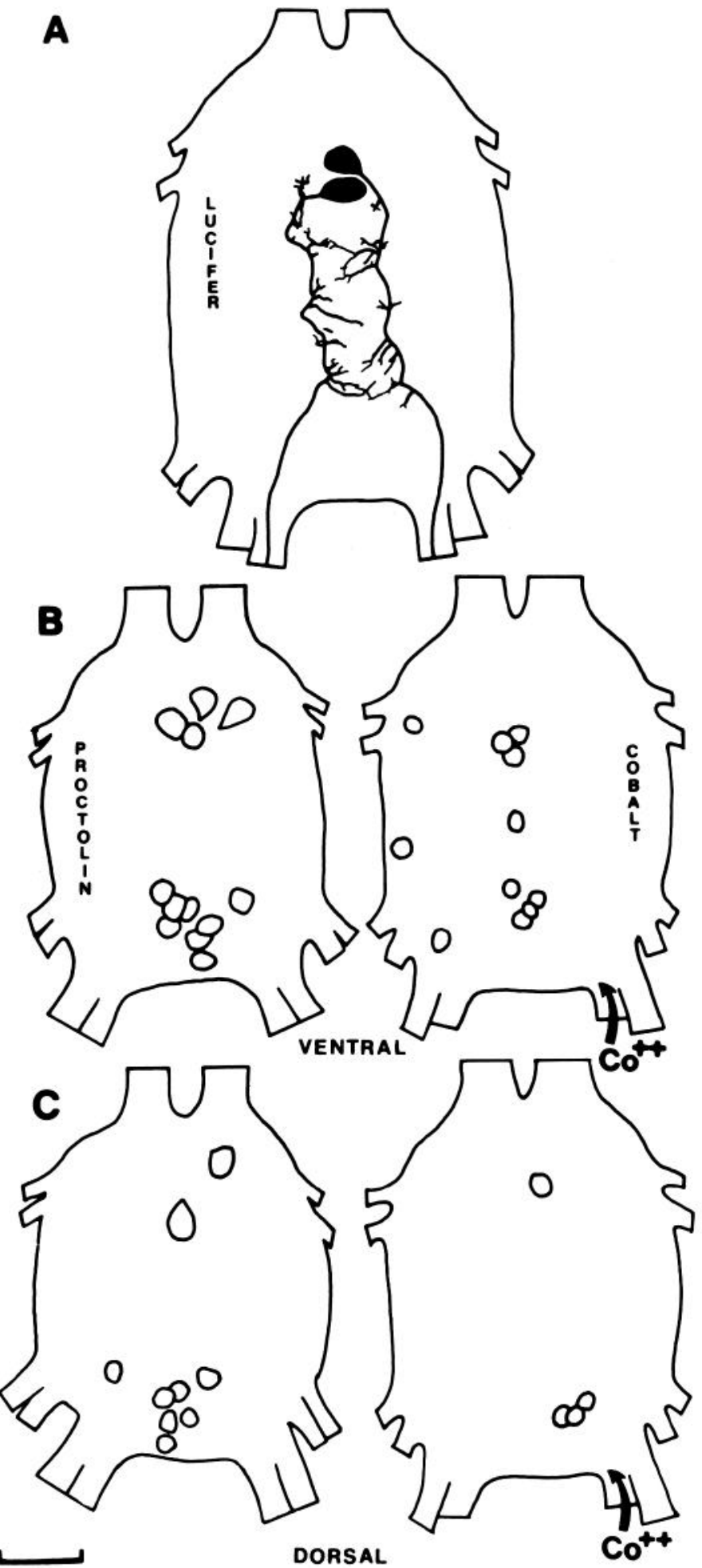

Figure 4. Terminal ganglion efferents to the hindgut. A, Two Lucifer Yellow dye-filled efferents from the AM cell cluster, illustrating their bilateral symmetry, $90 \%$ stage. $B$ and $C$, Comparison of the locations of ventral $(B)$ and dorsal $(C)$ cell bodies observed with either proctolin staining (left) or with cobalt backfills of the rectal nerve (right). The hindgut efferents were backfilled from one side only and represent half of the total efferent population. Note that some but not all of the cells that are backfilled can be accounted for by the pattern of proctolin staining. Proctolin staining of first instar ganglia, cobalt backfills of adult ganglia. Scale, $A$ to $C$ (left): $100 \mu \mathrm{m}$; $B$ and $C$ (right): $250 \mu \mathrm{m}$. 
surable proctolin is the appearance of immunoreactive neurons in the CNS.

The proctolin assayed during the second half of embryogenesis is displayed in Figure 1. The earliest embryonic proctolin was found in the $50 \%$ stage, when between 0.6 and $1.5 \mathrm{fmol} / \mathrm{embryo}$ are detected (range of five separate assays). Whole embryo levels increase at a rate of less than $1 \mathrm{fmol} /$ percent of development over the next $10 \%$ of embryogenesis, yielding by the $60 \%$ stage about $8 \mathrm{fmol} / \mathrm{embryo}$. The rate of proctolin accumulation then increases more than 5 -fold, and by the $70 \%$ stage there are about $60 \mathrm{fmol} /$ embryo. Proctolin amounts remain unchanged between the $70 \%$ and $75 \%$ stages but then increase again at $10 \mathrm{fmol} /$ percent of development. Whole embryo levels peak at $95 \%$ of development with approximately $250 \mathrm{fmol} / \mathrm{embryo}$. The levels then diminish over the last $5 \%$ of development and have declined by $20 \%$ in the hatchling.

Both the CNS and periphery contribute to the proctolin levels detected in whole embryos. However, the relative contribution shifts as the embryos develop (Fig. 1, solid versus open bars). Proctolin is first found in the CNS at the $50 \%$ stage and in the periphery at the $60 \%$ stage. Subsequently, peripheral levels rapidly outstrip the CNS proctolin. By the $90 \%$ stage peripheral proctolin has increased $300 \%$, but the CNS levels plateau by the $75 \%$ stage and remain relatively stable thereafter. The $20 \%$ depletion seen during the final $5 \%$ of embryogenesis is due to the loss of the neuropeptide outside the CNS; peripheral proctolin levels diminish by about 15 to $20 \%$ during this period, whereas CNS levels remain relatively stable. The early increases in proctolin can be interpreted as the result of its initial appearance in central neurons, whereas the later increases result from its accumulation in arborizations on peripheral targets.

The proctolin-like immunoreactivity present in central neurons soon after hatching is described in the preceding paper (Keshishian and O'Shea, 1985). There are approximately 70 immunoreactive cell bodies in the CNS, as well as extensive neuropilar arborizations. Some of these cells first stain during the first few hours after hatching and are rarely seen in embryos. These postembryonically appearing cells usually showed light to moderate immunoreactivity.

No neuronal staining is detected prior to the $60 \%$ stage. All of the central ganglia possess a dull, uniform fluorescence similar to the appearance of controls with blocked antiproctolin serum. The earliest immunoreactivity is faint staining in the neuropil of the brain at the $60 \%$ stage. At the $65 \%$ stage, staining can be seen in both subesophageal and prothoracic ganglia, while at the $70 \%$ stage proctolin staining is found in the mesothoracic, melathoracic, and terminal ganglia. This suggests a graded acquisition of the neuropeptide in an anterior to posterior sequence, which correlates to a similar sequence of ganglionic maturation (Bate, 1976; Bate et al., 1981). For each ganglion the number of staining cells remains constant during embryogenesis. The full embryonic complement of staining cell bodies appears abruptly during the brief period of development between the $60 \%$ and $70 \%$ stages. Subsequent to this there are increases in the intensity of staining, as well as in the elaboration of the neuropil.

Subesophageal ganglion. The immunoreactive cell bodies of the anterior medial (AM) cluster and the ventral medial (VM) pairs (Keshishian and O'Shea, 1985), which are typically seen in the postembryonic subesophageal ganglion, were not stained in the embryos. By contrast, the pattern of immunoreactive neuropil matched the postembryonic staining and is illustrated in Figure $2, A$ to $C$.

Early (65 to $70 \%$ stage) subesophageal neuropilar staining is weak (Fig. $2 A$ ) but steadily increases in intensity, with strong staining by the $80 \%$ stage (Fig. $2 B$ ). The basic outline of the mature postembryonic immunoreactivity is evident when staining begins at the $65 \%$ stage, when it consists of a few longitudinal and commissural processes (Fig. 2A). This basic outline is subsequently elaborated by the proliferation of processes and fine punctate or varicose bodies (Fig. 2, B and C). This process may represent the proliferation and maturation of synaptic contacts.

Thoracic ganglia. The postembryonic CNS staining in the thorax consists of (1) segmentally repeated ventral medial (VM) neurons in the pro-, meso-, and metathoracic ganglia; (2) anterior ventral lateral (AVL) neurons that may be motoneurons; and (3) posterior dorsal lateral (PDL) neurons in each of the three ganglia. Neuropilar staining is also extensive in the postembryonic ganglia, with dense arborizations derived from transganglionic axons passing through the proand mesothoracic ganglia, and neuropilar proctolin staining derived from the VM neurons in the metathoracic ganglion (Keshishian and O'Shea, 1985).

The development of proctolin staining in the neuropil of the thoracic ganglia (Fig. 2, $C$ and $D$ ) is very similar to that in the subesophageal ganglion. There is a graded increase in the intensity and an elaboration of fine processes and probable synaptic endings. The cell body staining in the pro- and mesothoracic ganglia was unreliable. In both ganglia the VM neurons were observed infrequently (about 10\%) in a few embryos older than $80 \%$ stage. Proctolin staining of the AVL neurons was not observed in any of the embryonic thoracic ganglia.

The metathoracic proctolin staining, from the $70 \%$ stage on, was very similar to that seen in the hatchling. Cell body staining, for both the VM neurons (Fig. $2 F$ ) and the PDL cells (Fig. $2 H$ ) is very reliable and was seen in $90 \%$ of the ganglia at all stages after staining commences (Fig. 2, $F$ to $H$ ). Neuropilar staining resembles that of the postembryonic ganglion and consists of the processes of both the anterior and posterior VM interneurons (the posterior VM arborization is illustrated in Fig. 2G).

Abdominal ganglia. The four small unfused abdominal ganglia do not have staining cell bodies at any stage of development, pre- or postembryonically. The large terminal abdominal ganglion, which is derived from the last four embryonic segments, has, by contrast, extensive postembryonic staining.

The postembryonic cell body staining within the terminal ganglion consists of two clusters of immunoreactive cell bodies. There are 6 AM neurons (refer to Fig. $5, A$ to $C$ ), whose axons can be traced as ipsilateral efferents into the cercal nerves, and there are 14 to 16 less strongly reactive posterior medial (PM) neurons. The AM neurons are present in the embryo, but the PM neurons first stain about 1 day after hatching (Keshishian and O'Shea, 1985).

Staining of the six AM neurons is evident from the $70 \%$ stage onward (Fig. 3, $A$ and $B$ ). The embryonic AM cell bodies are distributed in the same three patterns found in the postembryonic ganglion (Keshishian and O'Shea, 1985). These patterns are: (1) 6 ventral cells, 0 dorsal (about $50 \%$ occurrence); (2) 5 ventral, and 1 dorsal (about 25\%); and (3) 4 ventral and 2 dorsal (about 25\%). The three patterns, including their relative frequencies, are stable and evident from the $70 \%$ stage onward.

In summary, we can recognize four stages in the accumulation of proctolin in the embryonic CNS. The first stage consists of a steady increase, at the rate of about $1 \mathrm{fmol} /$ percent of development, from the $50 \%$ to the $60 \%$ stages. During this period no neuronal staining is seen in either the CNS or the periphery. The second stage runs from the $60 \%$ to $70 \%$ stage, where the rate of accumulation increases to about $5 \mathrm{fmol} /$ percent of development. This period corresponds to the establishment of staining in the CNS, as well as some early peripheral accumulation. The third stage is characterized by the most rapid increase ( $10 \mathrm{fmol} /$ percent of development) and is due to peripheral proctolin accumulation, and also correlates with the onset of peripheral staining (see below). The fourth and final stage consists of the $20 \%$ loss of proctolin in the periphery during the last $5 \%$ of embryogenesis and hatching. Although there is no immunocytological correlate of this loss, this period of embryonic development is characterized by strong muscular contractions prior to hatching (Bentley et al., 1979). The late decline in levels may therefore be due to the degradation of the released neurotransmitter. 

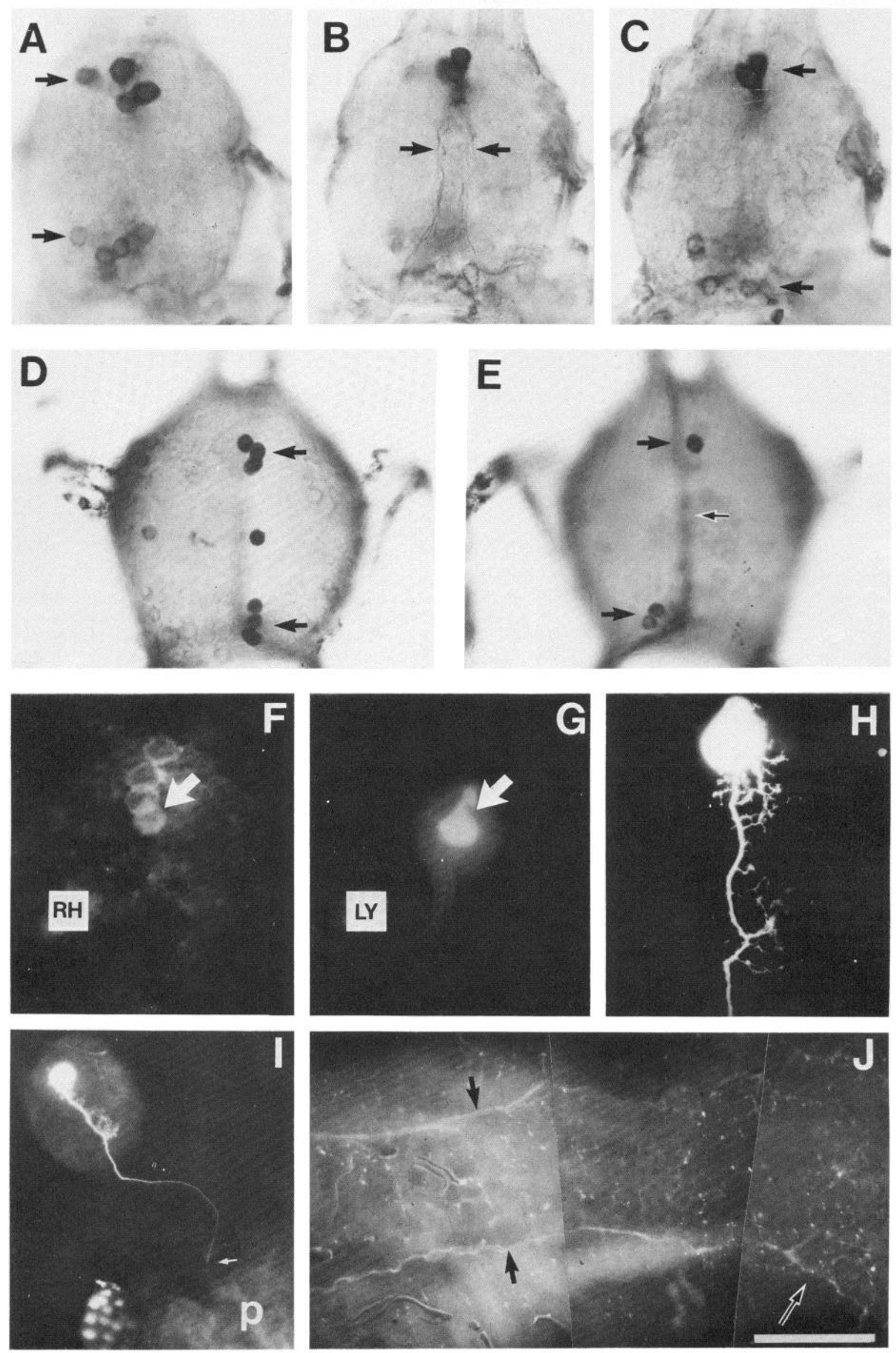

Figure 5 


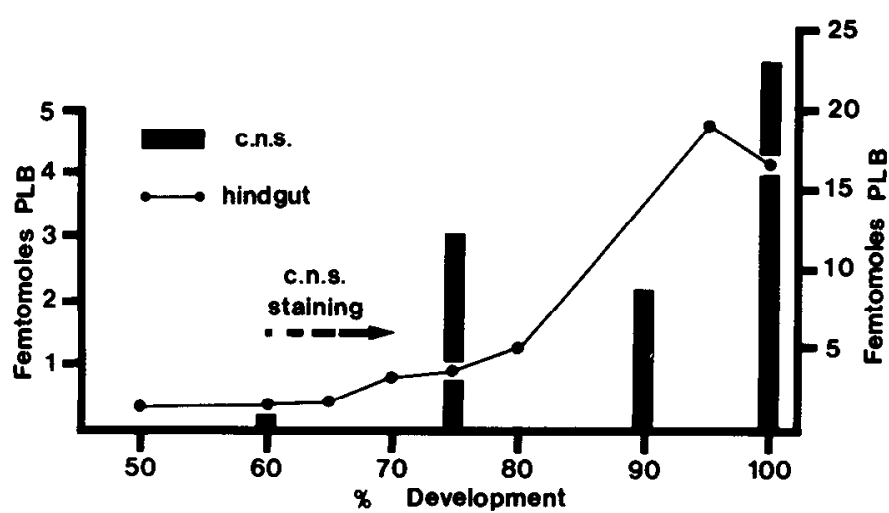

Figure 6. The developmental time course of proctolin accumulation in the embryonic hindgut, probably due to the accumulation of the neurotransmitter in the endings of the AM efferents. Proctolin is first detected at the $70 \%$ stage, when staining also commences in both the hindgut and the terminal ganglion. Proctolin levels (scale on the left) in the hindgut increase almost $300 \%$ over the next $25 \%$ of embryogenesis, but decline by almost a fifth during the final day before hatching, a phenomenon also seen for whole embryo levels. Black bars show selected CNS levels of proctolin for comparison (scale on right).

\section{Development of an identified proctolinergic neuromuscular system}

Our objective has been to establish model systems to study the development and function of proctolinergic neurons. Good candidates for studying neuromuscular synaptogenesis are the six proctolin-staining AM efferents of the terminal ganglion. They are large, accessible to microelectrode recording, and in the embryo are the sole central proctolin-staining neurons of the abdominal CNS. We have identified the peripheral targets of the AM cells and examined the anatomy of their embryonic terminal arborizations, the development of levels of proctolin at their targets, and the release of the neurotransmitter from their synapses.

A candidate peripheral target for the AM neurons is the intrinsic muscles of the hindgut. To test this, we followed two strategies. First, nerves from the terminal ganglion to the hindgut were isolated and backfilled with cobalt. This revealed the cell bodies of motoneurons with axons projecting to the hindgut, which were then compared to the maps of proctolin-staining cells. Second, we intracellularly impaled and filled with Lucifer yellow neurons in the region of the AM cell cluster (Fig. $3 C$ ) and determined their peripheral targets. We then co-labeled the dye fills for proctolin immunoreactivity, using rhodamine-coupled IgG as the fluorescent indicator. This doublelabeling method allowed us to determine the structure and targets of the proctolin-positive AM neurons.

Backfills of rectal nerve efferents. The rectal branch of the cercal nerve carries the major innervation of the intrinsic muscles of the hindgut (Seabrook, 1968). We backfilled both the rostral and caudal sub-branches of the rectal nerve in adult males and females; the pattern of efferent terminal ganglion somata is illustrated in Figures $4, B$ and $5, D$ and $E$. The number of cell bodies revealed by backfill on one side ranged from 9 to 16; in two-thirds of the backfills 15 cells were seen. Assuming bilateral symmetry, there are at least 30

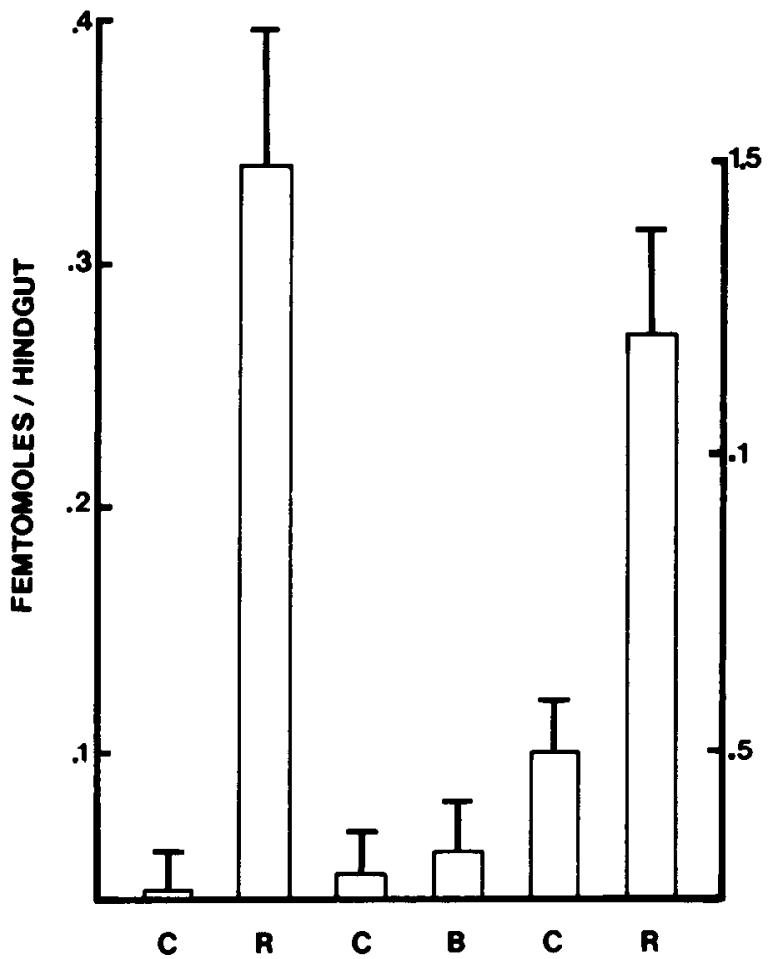

$\frac{w}{\omega}$

Figure 7. Calcium-dependent, potassium-stimulated proctolin release from hindgut nerve endings. Minimally dissected hindguts were collected and superfused, and the released proctolin was assayed as described under "Materials and Methods." A series of 10-min exposures to control saline (C), a release-inducing saline ( $R$ : with high $\mathrm{K}$ and normal $\mathrm{Ca}$ and $\mathrm{Mg}$ ), and a blocked release saline ( $B$ : with high $\mathrm{K}$ and no $\mathrm{Ca}$ and high $\mathrm{Mg}$ ) were tested in the sequence shown. Significant release of proctolin occurred only with the " $R$ " saline. Data are shown as the mean plus the $95 \%$ confidence interval, obtained from the dose-response curve linear regression. $C$, control saline $\left(5 \mathrm{mM} \mathrm{K}^{+}, 140 \mathrm{mM} \mathrm{Na}^{+}, 5 \mathrm{mM} \mathrm{Ca}{ }^{2+}, 1 \mathrm{mM} \mathrm{Mg}^{2+}\right) ; R$, release saline $(50 \mathrm{mM}$ $\left.\mathrm{K}^{+}, 95 \mathrm{mM} \mathrm{Na}^{+}, 5 \mathrm{mM} \mathrm{Ca}^{2+}, 1 \mathrm{mM} \mathrm{Mg}^{2+}\right) ; B$, blocked release saline $(50 \mathrm{mM}$ $\left.\mathrm{K}^{+}, 95 \mathrm{~mm} \mathrm{Na}^{+}, 0 \mathrm{~mm} \mathrm{Ca}{ }^{2+}, 6 \mathrm{mM} \mathrm{Mg}^{2+}\right)$.

efferent neurons with axons in the rectal nerve projecting to the hindgut musculature.

The staining revealed by cobalt backfills of the rectal nerve, when compared to the proctolin staining of the ganglion, shows that both the AM and PM neurons belong to a larger population of hindgut efferents. The unilateral backfills revealed four groups of neurons, two of which correspond to the proctolin-staining AM and PM cell clusters.

The first group of hindgut efferents revealed by unilateral backfills (Fig. 4, B and $C$, right) is located medially on the ventral and dorsal sides of the terminal ganglion, at the level of the 8th nerve, and its position overlaps the AM cluster (Figs. 4, $B$ and $C$, left, and 5, $A$ to $C)$. In four of six backfills there were three ventral cells and a single dorsal cell body. In one of these ganglia there was a fourth lightly stained ventral cell. The remaining two backfills had four ventral cells, but no dorsal cell. These data are consistent with the three patterns of ventral/dorsal proctolin staining seen for the six AM

Figure 5. The identification of the putative proctolin-staining motoneurons of the hindgut. $A$ to $C$. The cell body locations and central arborizations of the proctolin-staining neurons of the terminal ganglion, viewed from the ventral $(A)$ to the dorsal $(C)$ side of a 24-hr hatchling. The upper arrows in $A$ and $C$ indicate the AM cells; the lower arrows indicate the PM cells. The arrows in $B$ indicate the AM efferent axons. $D$ and $E$, The corresponding locations of cell bodies of hindgut motoneurons, revealed by unilateral cobalt backfills of the rectal nerve (refer to Fig. 4, $B$ and $C$ ). The middle arrow in $E$ indicates unidentified ascending axons from the hindgut. $F$ to $H$, The AM efferents to the hindgut, identified by intracellular Lucifer Yellow dye fills, can be co-labeled for proctolin. $F$, Proctolin staining with indirect rhodamine fluorescence $(R H)$, showing four of the six AM cells in this plane of focus. The arrow indicates the cell dye-filled with Lucifer Yellow. G, The cell body of the dye-filled AM neuron (arrow), viewed with Lucifer Yellow optics ( $L Y$ ); the axon and dendrites are out of the plane of focus. $H$. The same neurons as in $G$, focused on the axon and dendrites. $L$, Lucifer Yellow dye fill of an AM neuron, projecting its axon via the rectal branch of the cercal nerve to the proctodeum or hindgut $(P) ; 90 \%$ stage embryo. $J$, Proctolin staining of terminal ganglion axons on the intestinal and pyloric portions of the hindgut. Two axons (solid arrows) with lateral processes on the intestinal region are seen projecting profusely on muscle in the pyloric region of the hindgut (open arrows); $90 \%$ stage embryo. Scale, $=A$ to $C, F$ to $H$, and $J: 100 \mu \mathrm{m} ; D, E$, and $I: 250 \mu \mathrm{m}$. 
20 somata

$$
\begin{array}{lll}
\text { Br } & \text { S-T1 } & \text { T2-A5 } \\
\text { PLI } & \text { PLI } & \text { PLI }
\end{array}
$$

\begin{tabular}{ll} 
& $\begin{array}{l}\text { Hindgut } \\
\text { PLI }\end{array}$ \\
& $\begin{array}{l}\text { Peripheral } \\
\text { Periph. } \\
\text { proctolin } \\
\text { detected }\end{array}$ \\
\hline $2 x$ CNS
\end{tabular}

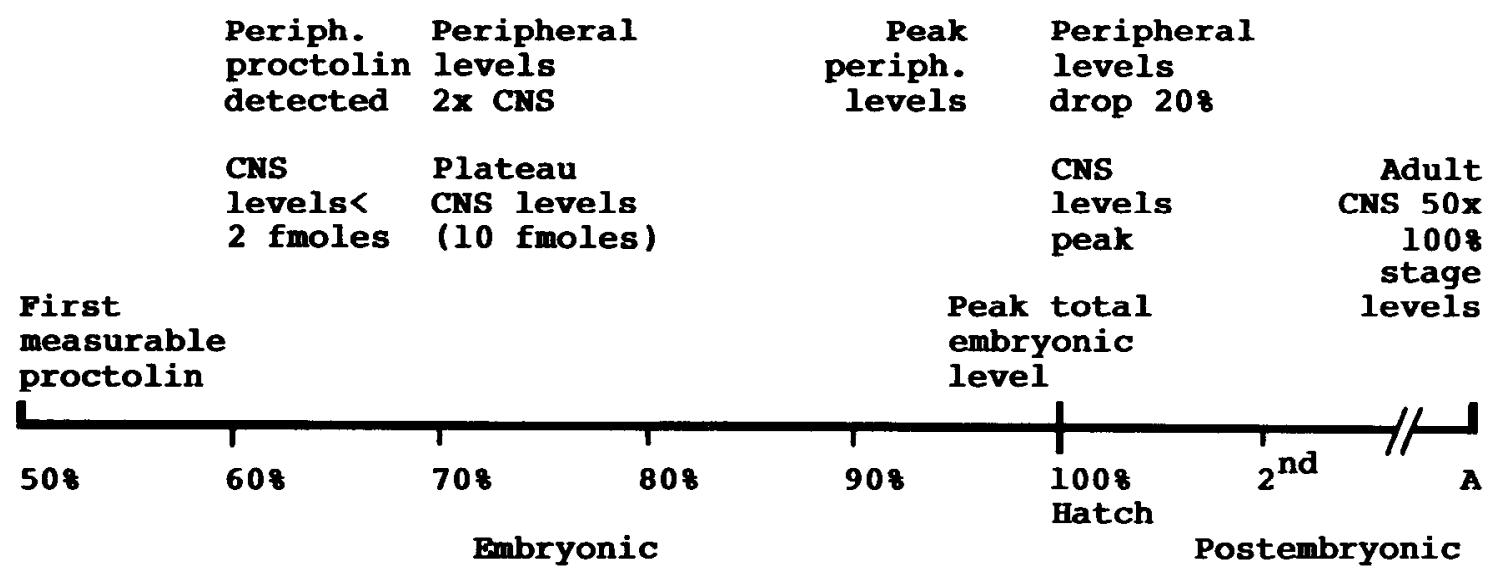

\section{0 somata}

Additional

PLI
Peak hindgut

levels

Figure 8. A time line of the embryonic and postembryonic expression of proctolin in the grasshopper, as determined by both immunochemistry and assay. Staging was according to Bentley et al. (1979); $5 \%$ of development $=$ about 1.3 days at $31^{\circ} \mathrm{C}$.

efferents and also imply the presence of two additional non-proctolinstaining efferents, that are clustered ventrally with the AM cells (see "Discussion"). This conclusion is also supported by the results of double-labeling experiments (see below).

The second group of hindgut efferents revealed by unilateral backfills (Fig. 4, $B$ and $C$, right) is located posteriorly at the level of the 9th nerve and consists of 7 or 8 dorsal and ventral neurons (14 to 16 if bilateral symmetry is assumed). These cells overlap with and have the same number (14 to 16) as the PM proctolin-staining cluster.

The other cells revealed by backfilling do not correspond to proctolin-immunoreactive neurons. In all cases a single median neuron is seen on the ventral side, located midway between the anterior and posterior clusters. Also, from one to three ventral, contralateral efferents were seen in five of six of the backfills (Fig. 4B).

The backfills strongly indicate that most or all of the PM cluster of proctolin-staining neurons project to the hindgut. In addition, it shows that the six AM neurons are probably a proctolin-staining subset of a larger cluster of at least eight hindgut motoneurons. Finally, there are about eight additional non-proctolin-staining motoneurons to the hindgut muscles.

Co-labeling of AM neurons. When living ganglia are viewed on the ventral side with contrast enhancement optics, we find 6 to 10 relatively large (about $25 \mu \mathrm{m}$ ) cell bodies located on the AM region of the terminal ganglion (Fig. $3 \mathrm{C}$ ). These cells are in the same position as the proctolin-staining AM neurons lying on the ventral side, and were selected as candidates for Lucifer Yellow dye fills and co-labeling. Concentrating on late $(90 \%$ stage) embryos, and restricting all of our dye fills to the ventral side, we found two types of neuroanatomy when these cells were impaled and dye-filled. The minority ( 13 of 63 dye fills; about $21 \%$ ) of cells dye-filled project their axons into the anterior connectives and may be intraganglionic interneurons. The balance (50 of 63 dye fills; about $79 \%$ ) are efferents, projecting their axons into the cercal nerve roots on the ipsilateral side (Figs. $4 A$ and $5, H$ and $/$ ). In ganglia where we attempted to identify all the ventral neurons from the cluster, up to 10 cells were dye-filled. We found the neurons of these ganglia divided into left and right ipsilateral efferents (the most seen were seven), as well as the anteriorly directed neurons. On two occasions we observed four efferents exiting through the cercal roots on one side. These observations confirm the evidence obtained from backfills, that the number of efferents can exceed the number of staining cells. We did not observe any other neuronal morphologies among these cells, nor did we observe any neurons on the ventral side with paired, bilaterally symmetrical axons, as is seen in the DUM cells.

The anatomy of the dye-filled embryonic efferents is indistinguishable from the postembryonic AM neuroanatomy (Fig. 5, $A$ to $C$ ). Like the AM neurons the dye-filled cell bodies were all located within 2 cell diameters of the midline, at the level of the 8th nerve roots. The dendrites are all directed medially and extend more than $50 \mu \mathrm{m}$ across the midline (Figs. $4 A$ and $5 H$ ). These dendrites overlap with their contralateral homologues, but we did not determine whether physical contact is actually made. Medial dendrites from the efferents are most abundant at two levels along the trajectories of the axons. The first arises posterior to the cell bodies, and the second is at the level of the 9th nerves (Figs. $4 \mathrm{~A}$ and $5 \mathrm{H}$ ). Outside of the neuropil the axons are smooth. The Lucifer yellow-filled efferent axons project directly to the ipsilateral side of the hindgut (Fig. 5/). The axons exit the compound cercal-epiproct nerve on the medial side, cross laterally into the cercal nerve, and project into the rectal branch of the cercal nerve, ending on the hindgut (Fig. 5/).

Having established that a subset of the dye fills projects to the hindgut, we then examined their staining for proctolin to confirm their identity as the AM cells. Efferent ventral neurons dye-filled with Lucifer yellow were co-labeled with anti-proctolin and demonstrated by indirect TRITC-IgG fluorescence. Success in co-labeling depended on meeting the following criteria: (1) the dye fill had to be traced into the nerve root, (2) the co-labeling had to be co-localized to the cell body of the dye fill, and (3) the full complement of the six ventral and dorsal immunoreactive AM neurons had to be seen. Thus, if by chance we had filled a neuron in a ganglion that had four ventral and two dorsal proctolin-staining cells, the entire complement of six was accounted for.

Figure $5, F$ to $H$, illustrates an example of combined anti-proctolin and Lucifer yellow co-labeling. In Figure $5 F$ the ventral side of the terminal ganglion is shown using rhodamine fluorescence optics ( $R H$; 540 to $550 \mathrm{~nm}$ excitation), where a candidate AM proctolinstaining efferent was dye-filled (Fig. 5F, arrow). In this ganglion four proctolin-staining neurons are observed on the ventral side; the other 
two lie dorsally out of the plane of focus (i.e., a 4 ventral +2 dorsal ganglion). Figure $5 G$ shows the same cells viewed under Lucifer yellow fluorescence optics ( $L Y ; 420$ to $440 \mathrm{~nm}$ excitation), revealing the dye-filled cell body (the neuritc and dendrites are out of the plane of focus). The overall anatomy is shown in Figure $5 \mathrm{H}$.

Five co-labeling experiments fulfilled the above criteria. The cell body positions revealed by immune staining in the co-labeling experiments corresponded to all three patterns. An additional two dye fills were obtained that stained fewer than the six cells. Finally, in a single example the dye-filled efferent neuron was not co-labeled, as shown by the presence of six other immunoreactive AM neurons. This is further evidence that in addition to the 6 staining AM cluster neurons, there are two very similar efferents that are not expressing proctolin.

Expression of proctolin in the AM innervation of the hindgut. We have provided several lines of evidence that strongly indicate that the six AM neurons, in addition to about two dozen other efferents, project to the hindgut. In the embryo, however, only the six AM neurons out of this population of about 30 are staining for proctolin We will now examine the development of proctolinergic innervation, presumably by these cells, on their embryonic motor targets.

The hindgut or proctodeum of the grasshopper is composed of an anterior pyloric region into which the Malphigian tubules empty, an elongated intestinal region, and the posterior rectum (Snodgrass, 1935). Extensive proctolin-like immunoreactivity is seen in all three regions of the hindgut, composed exclusively of axonal projections and terrminal arborizations. We found no immunoreactive neurons peripherally, indicating that innervation of the hindgut is exclusively from the CNS. Embryonic proctolin-like immunoreactivity was examined in hindguts from the $60 \%$ stage onward at $10 \%$ developmental intervals. Staining was detected from the $70 \%$ stage $(n=5)$ over the entire hindgut, but most reliably in the pyloric and intestinal regions. The intensity of staining of axons increases from the $70 \%$ to $90 \%$ stage and is constant thereafter. The immunoreactive axons from the rectal nerve project along the axis of the intestine, with lateral processes directed transversely over its surface (Fig. $5 \mathrm{~J}$, solid arrows). The intestinal portion of the hindgut is composed of six longitudinal muscle bundles, and each bundle had a proctolinstaining axon. The anteriorly directed proctolin-staining axons project onto the pyloric region, where they arborize extensively (Fig. $5 \mathrm{~J}$, open arrow).

Proctolin accumulation in the hindgut resembles that of the whole embryo but first appears at a later stage (cf. Figs. 6 and 1). From the $50 \%$ to the $65 \%$ stages the levels of the hindgut are subthreshold (about $0.25 \mathrm{fmol} /$ hindgut; $n=5$ determinations). The earliest measurable levels are found at the $70 \%$ stage, when staining first appears in the AM cells. There is a $300 \%$ increase in hindgut proctolin between the $80 \%$ and $95 \%$ stages; the hindgut levels in $100 \%$ stage hatchlings are depleted approximately $20 \%$ from their $95 \%$ stage pre-hatching levels.

Release of proctolin from the hindgut. We have presented anatomical evidence that the $\mathrm{AM}$ neurons are the proctolin-staining motoneurons of the embryonic hindgut. We have tested this by showing that there is calcium-dependent release of proctolin from the hindgut at the end of embryogenesis.

Figure 7 shows calcium-dependent proctolin release induced by depolarization with elevated $\mathrm{K}^{+}$concentration. A 10-min perfusion with $50 \mathrm{~mm} \mathrm{~K}^{+}$results in a $700 \%$ increase in proctolin release above control levels; in the absence of calcium, however, there is no signiticant increase in release. About $1.5 \%$ of the total available hindgut proctolin was released under these conditions.

In summary, we have examined the development of proctolin expression in a defined motor target. The hindgut is innervated by about 30 motoneurons from the terminal ganglion, only 6 of which are proctolin immunoreactive in the embryo. The six AM axons establish a dense proctolin-staining arborization over the intrinsic muscle fibers, especially on the six intestinal muscle bundles and on the pyloric regions. Proctolin begins to accumulate in these endings at the same time that staining is first seen in the CNS. Over the next $25 \%$ of embryogenesis there is a $300 \%$ increase in the amount of proctolin found in the hindgut. The embryonic changes in hindgut proctolin levels resemble the changes seen in overal peripheral proctolin. Thus, the accumulation of the transmitter within these cells may typify the behavior of most proctolin-staining motoneurons. Finally, when assayed at the end of embryogenesis, we have found that the proctolin at the hindgut can be released in a calcium-dependent fashion when the cells are depolarized, implying that the cellular mechanism for releasing the transmitter is in place and functional when the animal hatches.

\section{Discussion}

Our goal has been to describe the acquisition and expression of a peptide neurotransmitter in the grasshopper embryo, both in uniquely identified central neurons and at peripheral synapses. Proctolin appears relatively late in embryonic development, as do other neurotransmitters in this system, such as octopamine and serotonin (Goodman et al., 1979; Taghert and Goodman, 1984). This suggests that transmitter phenotypes in general arise late in the course of neuronal development.

The onset of neurotransmitter expression. We used two methods to time the onset of proctolin expression in embryos. The bioassay method detected proctolin at the $50 \%$ stage of development (Fig. 8). The immunochemical staining for proctolin appears to be less sensitive and lags the onset of proctolin expression by about $10 \%$ of development. Staining begins in the brain at the $60 \%$ stage, and overall CNS staining occurs by the $70 \%$ stage. The two methods, however, complement and confirm each other, and provide different glimpses of the same developmental events in the embryo. For example, the sharp increase in the rate of proctolin accumulation at the $60 \%$ stage corresponds to the onset of CNS staining. Similarly, increases in peripheral levels after the $70 \%$ stage parallel the onset of peripheral staining, as was clearly demonstrated in the hindgut. Nevertheless, developmental studies based solely on staining may not accurately time the onset of phenotypic expression.

Proctolin staining in the nerve cord arises in an anterior to posterior sequence, beginning in the brain and extending to the terminal ganglion over the next $10 \%$ of development. This is consistent with the anterior to posterior gradient in neuronal maturity observed in the grasshopper CNS. This time gradient has been found for neuronal birth dates, onset of axonogenesis, acquisition of mature cellular morphology, electrical activity, and synaptogenesis (Bate, 1976; Bate et al., 1981; Goodman and Spitzer, 1981b, Shankland and Goodman, 1982). Thus, the onset of staining reflects the maturity of neurons within each ganglion, where the timing of expression is set according to a developmental schedule followed by each neuron. There are several studies that suggest that CNS neurons in this organism acquire their mature phenotypes through a common sequence of developmental events. During the $60 \%$ to $70 \%$ stages of development, when proctolin staining arises, interneurons and motoneurons have acquired most of their central neuroanatomy (Goodman and Spitzer, 1979; Bentley and ToroianRaymond, 1981; Shankland and Goodman, 1982), have acquired active membrane properties (Goodman and Spitzer, 1981b), and have begun to make synapses (Goodman and Spitzer, 1979; Heathcote, 1981; Shankland and Goodman, 1982). We therefore place the onset of proctolin expression at a time in neuronal differentiation when central and peripheral synaptic targets are being established. This implies that the onset of transmitter synthesis is timed to coincide with the genesis of synapses and synaptic machinery in the embryo. These observations are consistent with those made by Taghert and Goodman (1984) for serotonin, and by Goodman et al. (1979) for octopamine; for each neurotransmitter there is a relatively late expression that is temporally correlated with the period in CNS development when synaptogenesis occurs.

The pattern of neuronal expression. The expression of proctolin is a neuronal specialization that arises in a small and conserved 
subset of ganglionic neurons. The neurons that do stain are the same identifiable cells in each individual that have been uniquely determined for the expression of this neurotransmitter. Several developmental fcatures characterize the staining of the proctolinergic neurons. For each cell there is a characteristic time in development when staining commences. The staining appears in each cell suddenly, with no evidence for supernumerary staining. Thus, once staining commences in a neuron (whether in the embryo or the hatchling), it remains proctolin positive throughout postembryonic development.

With the exception of changes in the size of cells and in the addition of fine processes and synaptic endings, the late postembryonic pattern of neuropilar staining is established by the $70 \%$ stage of embryogenesis. The constancy of the neuropilar proctolin staining reflects the fact that dendritic and axonal anatomy in general stabilizes in late embryogenesis, as is seen in a variety of uniquely identified ganglionic neurons (e.g., Bentley and Toroian-Raymond, 1981; Goodman and Spitzer, 1979; Raper et al., 1983). By contrast, the number of cell bodies staining at $70 \%$ is a subset of the mature roster, with some additional cell bodies staining soon after hatching. As ventral nerve cord neurons arise during a relatively short period of development during embryogenesis (Bate, 1976; Bate and Grunewald, 1981), we can rule out the possibility that the additional staining is due to postembryonic cell births. Of the cell bodies that begin to stain postembryonically, the majority have moderate and/ or variable staining features. We therefore do not rule out the possibility that these neurons may also express proctolin embryonically, at levels too low for immunoreactivity, and that after hatching their proctolin content has increased to detectable levels. The time course of transition from non-staining to staining among the neurons that appear postembryonically was determined for the terminal ganglion PM motoneurons. When ganglia from siblings were fixed at 12 - to 16 -hr intervals (equal to 2 to $3 \%$ of embryogenesis) for 100 hr post-hatching, the transition was sudden and complete by 24 to $36 \mathrm{hr}$.

Peripheral proctolin and its source. Peripheral levels of the neuropeptide increase substantially during the last 25 to $30 \%$ of embryogenesis and constitute from 80 to $90 \%$ of total embryonic proctolin by hatching. The peripheral accumulation of proctolin is consistent with the view that it is a neuromuscular transmitter for some motoneurons (Adams and O'Shea, 1983; Witten et al., 1984). Peripheral proctolin probably accumulates in motor endings and, to a lesser extent, in peripheral cell bodies which have been found in the foreand midgut of the cockroach and are probably present in the grasshopper (Witten et al., 1984). In the hindgut there is evidence for substantial proctolin accumulation in motor endings during late embryogenesis. The levels observed from the $80 \%$ to $95 \%$ stages increase more than 4-fold, whereas the peripheral neuroanatomy remained apparently constant. There was also a $20 \%$ decline in peripheral proctolin during the $5 \%$ of development preceding hatching, during which period there is substantial motor activity in the gut and embryo in general. These losses suggest that proctolin was released from the hindgut synapses and degraded. The evidence from the release experiments is consistent with this view. Sizable neurotransmitter release in the hindgut may be induced by calciumdependent depolarization during this final stage of embryonic development.

We identified by means of dye fills the CNS location of about 30 motoneurons in the terminal ganglion that innervate the hindgut, including those that are proctolin staining. The identification of the proctolin-staining subset was based upon both co-labeling and by matching cell body positions in ganglia stained for proctolin with those that were backfilled.

The fraction of motoneurons innervating the hindgut that expresses proctolin is relatively high $(70 \%)$, when compared to the percentage of proctolin staining innervation of skeletal muscle (about $10 \%$ of skeletal motoneurons; Witten et al., 1984; Keshishian and O'Shea, 1985). This suggests a physiological similarity between those skeletal muscle fibers that are innervated by proctolin motoneurons and the proctolin-innervated gut musculature. Indeed, proctolin-staining skeletal motoneurons have been shown to innervate preferentially both tonic and myogenically active muscle fibers (Adams and O'Shea, 1983; Witten et al., 1984). These are physiological features also associated with gut muscle fibers.

We note broad interspecies homologies in the numbers, cell body positions, and apparent neuroanatomy of grasshopper hindgut motoneurons with those mapped in the cockroach by Eckert et al. (1981) and by Brown and Nagai (1969). The grasshopper and cockroach motoneuron innervations of the hindgut muscles are clearly related structurally and may also be homologous at the level of single identified neurons. The pattern of proctolin immunoreactivity among these neurons was determined for the cockroach by both Eckert et al. (1981) and Bishop and O'Shea (1982). The proctolin staining among the hindgut motoneurons of the cockroach is, however, different from that of the grasshopper, with overlap found in only a fraction of the PM neurons (the "type 2" efferents of Eckert et al., 1981). We conclude that, despite the apparent conservation of neuronal number and general neuroanatomy, the transmitter expression has diverged between the two species. This divergence in transmitter choice among similar neurons may also have occurred in the other ventral ganglia, where there is limited interspecies homology at the level of proctolin expression (Keshishian and $\mathrm{O}^{\prime}$ Shea, 1985). This suggests that reassigning transmitter fates in neurons is a possible strategy used in the evolution of neuronal circuits. That neurotransmitter phenotypes are labile and can be switched is well known both in vivo (Le Douarin, 1980; Landis and Keefe, 1983) and in vitro (Patterson and Chun, 1977; Wolinsky and Patterson, 1983), and in the insect this may occur as a means of tailoring a less easily alterable neuronal circuit to the adaptive needs of an organism.

The AM cells provide an interesting example of the kinds of variability that may occur within a cluster of anatomically similar cells. The eight motoneurons comprise an "identified cluster," as defined by Goodman (1976), where a given cell type having a characteristic position, physiology, and morphology is repeated a fixed number of times, to form a unique population of structurally similar neurons. However, within the AM cluster of eight bilaterally symmetrical motoneurons are three pairs specialized for proctolin expression. These six cells are, in turn, subject to three patterns of cell body location. The dye fills indicate that the three dorsoventral patterns are probably due to a translocation of up to two AM cell bodies. The translocation may be caused by the dorsoventral displacement of cell bodies that occurs when the four segments of the compound terminal ganglion fuse between the 40 and $70 \%$ stages (Shankland, 1981). The AM cells therefore provide a "natural experiment" to test the role of cell position in the determination of neuronal phenotype. That three positional patterns can all result in the same transmitter phenotype suggests that the dorsoventral cell body position is probably not a significant factor at the time of proctolin expression, that is, at the $70 \%$ stage. Thus, if there is a dorsoventral positional basis for the determination of the proctolin phenotype, its influence probably occurs prior to the cell body displacement, and possibly soon after cell birth. Both Taghert and Goodman (1984) and Kuwada and Goodman (1983) have shown that specific neuronal phenotypes, including both transmitter and the morphology of identified neurons, are probably determined by the time of cell birth or soon thereafter.

Finally, the strong morphological similarities of the AM neurons, and the fact that they form a single median cluster sharing in common a neurotransmitter, suggests similarities to the DUM cells, which have a common precursor neuroblast (Goodman and Spitzer, 1979). However, unlike the DUM cells, it is probable that the AM efferents arise from at least two and possibly more precursor neuroblasts. Central neurons in grasshopper embryos are generated either as single pairs from midline precursor (MP) cells (Bate and Grunewald, 1981) or as groups of clonally related cells budded from 
the neuroblast cells (Bate, 1976). Bilateral symmetry in neurons (as in the AM cluster) derives from symmetrical neurogenesis from bilateral pairs of homologous neuroblasts. If the AM neurons are derived from neuroblasts, at least two would be needed to generate a single bilaterally symmetrical cluster of cells. If the AM cells have MP origins, even more precursors would be involved. We are currently investigating the embryonic cell lineages to determine how the AM cluster arises.

\section{References}

Adams, M. E., and M. O'Shea (1983) Peptide cotransmitter at a neuromuscular junction. Science 221: 286-289.

Bate, C. M. (1976) Embryogenesis of an insect nervous system. I. A map of the thoracic and abdominal neuroblasts in Locusta migratoria. J. Embryol. Exp. Morphol. 35: 107-123.

Bate, C. M., and E. B. Grunewald (1981) Embryogenesis of an insect nervous system. II. A second class of neuron precursor cells and the origin of the intersegmental connectives. J. Embryol. Exp. Morphol. 61: 317-330.

Bate, C. M., C. S. Goodman, and N. C. Spitzer (1981) Embryonic develop ment of identified neurons: Segment-specific differences in the $\mathrm{H}$ cell homologues. J. Neurosci. 1: 103-106.

Bentley, D., and M. Caudy (1983) Navigational substrates for peripheral pioneer growth cones: Limb-axis polarity cues, limb-segment boundaries and guidepost neurons. Cold Spring Harbor Symp. Quant. Biol. 48: 573585.

Bentley, D., and H. Keshishian (1982) Pathfinding by peripheral pioneer neurons in the grasshopper. Science 218: 1082-1088.

Bentley, D., and A. Toroian-Raymond (1981) Embryonic and postembryonic morphogenesis of a grasshopper interneuron. J. Comp. Neurol. 201: 507518.

Bentley, D., H. Keshishian, M. Shankland, and A. Toroian-Raymond (1979) Quantitative staging of embryonic development of the grasshopper, Schistocerca nitens. J. Embryol. Exp. Morphol. 54: 47-74.

Bishop, C. A, and M. O'Shea (1982) Neuropeptide proctolin (H-Arg-Tyr-LeuPro-Thr-OH): Immunocytochemical mapping of neurons in the central nervous system of the cockroach. J. Comp. Neurol. 207: 223-238.

Bishop, C. A., R. J. Miller, and M. O'Shea (1981) Neuropeptide proctolin (HArg-Tyr-Leu-Pro-Thr-OH): Immunological detection and neuronal localization in the insect central nervous system. Proc. Natl. Acad. Sci. U. S. A. 78: 5899-5902.

Brown, B. E. (1975) Proctolin: A peptide transmitter candidate in insects. Life Sci. 17: $1241-1252$.

Brown, B. E., and T. Nagai (1969) Insect visceral muscle: Neural relations of the proctodeal muscles of the cockroach. J. Insect Physiol. 15: 17671783.

Davis, N. T. (1982) Improved methods for cobalt filling and silver intensification of insect motor neurons. Stain Tech. 57: 239-244.

Eckert, M., H. Agricola, and H. Penzlin (1981) Immunocytochemical identification of proctolin-like immunoreactivity in the terminal ganglion and hindgut of the cockroach Periplaneta americana. Cell Tissue Res. 217: 633-645.

Goodman, C. S. (1976) Constancy and uniqueness in a large population of small interneurons. Science 193: 502-504.

Goodman, C. S., and N. C. Spitzer (1979) Embryonic development of identified neurones: Differentiation from neuroblast to neurone. Nature 280: 208-214

Goodman, C. S., and N. C. Spitzer (1981a) The mature electrical properties of identified neurones in grasshopper embryos. J. Physiol. (Lond.) 313: 369-384.

Goodman, C. S., and N. C. Spitzer (1981b) The development of electrical properties of identified neurones in grasshopper embryos. J. Physiol. (Lond.) 313: 385-413

Goodman, C. S., M. O'Shea, R. E. McCaman, and N. C. Spitzer (1979) Embryonic development of identified neurons: Temporal pattern of morphological and biochemical differentiation. Science 204: 1219-1222.

Goodman, C. S. M. Bate, and N. C. Spitzer (1981) Embryonic development of identified neurons: Origin and transformation of the $\mathrm{H}$ cell. J. Neurosci. 1: $94-102$.

Heathcote, D. (1981) Differentiation of an identified sensory neuron (SR) and associated structures (CTO) in grasshopper embryos. J. Comp. Neurol. 202: 1-18.

Keshishian, $H$. (1980) Origin and morphogenesis of pioneer neurons in the grasshopper metathoracic leg. Dev. Biol. 80: 388-397.

Keshishian, H., and D. Bentley (1983) Embryogenesis of peripheral nerve pathways in grasshopper legs. III. Development without pioneer neurons. Dev. Biol. 96: 116-124.

Keshishian, $H_{\text {., }}$ and M. O'Shea (1985) The distribution of a peptide neurotransmitter in the postembryonic grasshopper central nervous system. J. Neurosci. 5: 992-1004.

Kuwada, J. Y., and C. S. Goodman (1983) Neuronal determination during embryonic development: Heirarchical fate of two sibling cells in the grasshopper CNS. Soc. Neurosci. Abstr. 9: 899.

Landis, S. C., and D. Keefe (1983) Evidence for neurotransmitter plasticity in vivo: Developmental changes in properties of cholinergic sympathetic neurons. Dev. Biol. 98: 349-372.

Le Douarin, N. M. (1980) The ontogeny of the neural crest in avian embryo chimaeras. Nature 286: 663-669.

Patterson, P. H., and L. L. Y. Chun (1977) The induction of acetylcholine synthesis in primary cultures of dissociated rat sympathetic neurons. Dev. Biol. 56: 263-280.

Raper, J., M. J. Bastiani, and C. S. Goodman (1983) Pathfinding by neuronal growth cones in grasshopper embryos. I. Divergent choices made by growth cones in sibling neurons. J. Neurosci. 3: 20-30.

Seabrook, W. D. (1968) The innervation of the terminal abdominal segments (VIII-XI) of the desert locust, Schistocerca gregaria. Can. Entomol. 100: $693-715$

Shankland, M. (1981) Development of a sensory afferent projection in the grasshopper embryo. I. Growth of peripheral pioneer axons within the central nervous system. J. Embryol. Exp. Biol. 64: 169-185.

Shankland, M., and C. S. Goodman (1982) Development of the dendritic branching pattern of the medial giant interneuron in the grasshopper embryo. Dev. Biol. 92: 489-506.

Snodgrass, R. E. (1935) Principles of Insect Morphology, McGraw-Hill, New York.

Taghert, P. H., and C. S. Goodman (1984) Cell determination and differentiation of identified serotonin-immunoreactive neurons in the grasshopper embryo. J. Neurosci. 4: 989-1000.

Taghert, P. H., C. Q. Doe, and C. S. Goodman (1984) Cell determination and regulation during development of neuroblasts and neurones in grasshopper embryos. Nature 307: 163-165.

Witten, J., M. K. Worden, M. Schaffer, and M. O'Shea (1984) New classification of insect motoneurons: Expression of different peptide transmitters. Soc. Neurosci. Abstr. 10: 151.

Wolinsky, E., and P. H. Patterson (1983) Tyrosine hydroxylase activity changes with induction of cholinergic properties in cultured sympathetic neurons. J. Neurosci. 3: 1495-1500. 